\title{
REPRESENTAÇÕES SOCIAIS SOBRE O TRABALHO DOCENTE: CONCEPÇÕES DE CIDADANIA DE PROFESSORES DA REDE ESTADUAL DE MG NO ANO DE 2014
}

\author{
SOCIAL REPRESENTATIONS ON TEACHING WORK: CONCEPTIONS OF \\ CITIZENSHIP OF TEACHERS OF THE STATE NETWORK OF MG IN THE YEAR 2014
}

Doan Ricardo Neves da Cruz ${ }^{1}$

\begin{abstract}
RESUMO: Este artigo discute algumas representações sociais de professores de História atuantes em escolas estaduais no interior de Minas Gerais, no período do ano letivo de 2014. Para sua realização, propôs-se a análise de concepções atribuídas ao trabalho docente no ensino de História, principalmente no que diz respeito à questão da cidadania. Esta investigação está fundamentada na teoria das representações sociais e em um referencial metodológico qualitativo, com o emprego de observações das aulas de História, anotações em diário de campo e realização de entrevistas com cinco docentes da rede pública ao longo de um ano letivo. As representações em torno da cidadania apresentam alguns problemas e ambiguidades, mas também mostram o papel de estabilizar as significações quanto ao trabalho docente, diante da precarização e da desvalorização da profissão de professor.
\end{abstract}

Palavras-chave: Representações sociais. Ensino de história. Trabalho docente.

\begin{abstract}
This paper aims to discuss some social representations of history teachers who work in public schools in the state of Minas Gerais. In order to do it, I proposed to analyze their conceptions about the history teaching practice, particularly the ones involving the idea of citizenship. This investigation is based on both Social Representation Theory and a qualitative methodological framework, which was developed from the classroom observation, daily notes, and interviews with five teachers along the school year. The representations over the citizenship have presented some issues and ambiguities, but also have showed that are responsible for reinforcing and balancing the notions of the teacher's role in education, especially with the devaluation of educators and their precarious working conditions.
\end{abstract}

Keywords: Social representation. History teaching. Teaching practice.

1 Professor da Educação Básica de Minas Gerais. Mestre em Educação pela Universidade Federal de Ouro Preto (UFOP). 


\section{Introdução}

Em uma aula de História, para uma turma de cerca de trinta alunos do 30 ano do Ensino Médio, sobre o governo do presidente Getúlio Vargas, um jovem professor iniciante explicava a importância das conquistas trabalhistas do período, quando sua fala foi interrompida por um aluno curioso, o qual perguntou sobre como o docente tornara-se professor de História e por que havia feito tal escolha profissional. O professor permanece silencioso e pensativo por alguns instantes, talvez hesitando em pausar a explicação, mas resolve responder a pergunta e começa a narrar brevemente seu percurso de escolha e formação inicial.

Esse pequeno recorte de um diário de campo nos mostra como os professores podem ser interpelados, sobretudo em seu cotidiano de trabalho, acerca dos motivos da escolha profissional. Nesse sentido, algumas representações sobre o próprio ofício podem emergir a partir das revisões, ressignificações e reatualizações acerca do porquê da opção profissional pelo trabalho docente no ensino público. Em outros momentos, ainda dentro da sala de aula, os professores são conduzidos a explicar e ressaltar a importância de sua disciplina escolar para conseguir a participação e o envolvimento de seus alunos nas atividades propostas, e nessas situações também surgem representações sobre o ofício que destacam a questão da formação para a cidadania.

Com base em uma pesquisa que investigou as representações sociais de cinco professores de História, atuantes na rede pública estadual de três cidades do interior de Minas Gerais (Ouro Preto, Mariana e Diogo de Vasconcelos, localizadas na chamada Região dos Inconfidentes), o presente artigo discute algumas concepções atribuídas ao trabalho docente, principalmente no que diz respeito à questão da cidadania. Inicialmente, explicitamos alguns pressupostos teóricometodológicos que pautaram nossa investigação para, em seguida, problematizar algumas representações sociais observadas com os professores participantes, discutindo as diferentes dimensões das concepções de cidadania que foram associadas ao ensino de História. ${ }^{2}$

\footnotetext{
2 Agradecemos aos professores da rede pública que participaram do presente estudo e dispuseram suas aulas e seu tempo de trabalho para a observação, para preenchimento de questionários e para realização das entrevistas. Apesar da precariedade do ensino público e da complexidade do ambiente de trabalho, esses docentes permitiram o acesso à sua vida profissional para a
} 


\section{Percursos teórico-metodológicos sobre as representações sociais}

O conhecimento histórico escolar, ao trabalhar com a experiência humana no tempo, envolve representações em conflito, assim como mobilizações, interpretações e usos do passado. No processo de trocas simbólicas que envolvem uma aula de História, os pontos de vista e sentidos atribuídos ao próprio ofício, pelo professor, também afetam a prática profissional. Considerando essa perspectiva de análise, as formulações teóricas sobre as representações sociais permitem uma aproximação ao dinamismo do cotidiano da sala de aula e das práticas docentes, possibilitando 0 estudo dos significados socialmente construídos, ao abranger sujeitos, objetos, fatos, ideias e teorias (MADEIRA, 1997).

A teoria das representações sociais originou-se dos trabalhos do psicólogo social Serge Moscovici na Europa na década de 1960, em meio aos debates teóricos sobre as relações entre os fenômenos do nível individual e do nível coletivo. Segundo o autor, as representações sociais teriam a função de tornar familiar o não-familiar, uma vez que a dinâmica das relações estaria fundamentada na familiarização, nos universos consensuais em relação aos quais os objetos, sujeitos e fatos, são percebidos de acordo com padrões prévios e paradigmas, sob a influência da tradição, da repetição e da memória (MOSCOVICI, 2004).

Partindo das formulações de Moscovici, a autora francesa Denise Jodelet foi uma das grandes responsáveis pelo aprofundamento teórico do conceito, que se difundiu em diferentes áreas, sobretudo a partir dos anos 1980. Para a autora, as representações sociais configuram-se como uma forma de conhecimento estruturado em sistemas de interpretação que atuam sobre a relação dos sujeitos com o mundo e com os outros indivíduos (JODELET, 1989). Elas contribuiriam para guiar na medida em que identificam, interpretam e definem diferentes elementos da realidade, a partir dos quais são retirados significações e saberes pelos grupos sociais:

investigação, colaborando de forma inestimável para as reflexões deste texto. Os pseudônimos foram escolhidos pelos próprios professores, como estratégia para se reconhecerem na pesquisa. 
[...] a abordagem de representações sociais pode fornecer, para uma mudança social ao nível individual ou coletivo e qualquer que seja o domínio de intervenção, a melhor contribuição, mas também a mais difícil. A melhor, porque os modos que os sujeitos possuem de ver, pensar, conhecer, sentir e interpretar seu modo de vida e seu estar no mundo têm um papel indiscutível na orientação e na reorientação das práticas. A mais difícil, pois as representações sociais são fenômenos complexos, incitando um jogo de numerosas dimensões que devem ser integradas em uma mesma apreensão e sobre as quais é necessário intervir conjuntamente (JODELET, 2009, p. 695)

Ainda, segundo a autora, nos conteúdos representacionais relativos ao objeto representado, haveria três tipos de efeitos: as distorções, que acentuam ou diminuem certos atributos de um objeto ou situação, durante o processo de análise de suas qualidades; a suplementação diz respeito à atribuição de elementos e conotações que não pertencem ao objeto representado; o desfalque designa a supressão de elementos pertencentes ao objeto ou situação representada (JODELET, 1989).

As representações sociais no campo da educação configuram-se como uma vertente de investigações que tem se expandido progressivamente nas últimas décadas, pois ao focalizar questões relativas ao imaginário, às condutas e práticas sociais, estruturam-se como estudos relevantes na análise dos mecanismos que interferem no processo educativo, captando com mais profundidade como pensam os atores de um contexto escolar determinado, ou ainda como os processos simbólicos e sistemas de significação socialmente enraizados interferem na interação educativa (ALVEZ-MAZZOTTI, 2008).

Com base nesse potencial teórico-metodológico das representações sociais, foi desenvolvida uma investigação que abrangeu cinco professores de História atuantes na rede estadual de três cidades localizadas no interior de Minas Gerais (Mariana, Ouro Preto e Diogo de Vasconcelos), cada um lecionando em uma instituição diferente e com distintos tempos de experiência profissional. Estruturada como uma pesquisa qualitativa com abordagem de cunho etnográfico (ANDRÉ, 1995), foram produzidos diários de campo, de observação das aulas dos docentes participantes, que tentavam descrever densamente o cotidiano das aulas de História durante os três ou quatro meses em que foram feitas as observações da atuação de cada um deles. 
Ao final desse período de acompanhamento, foram realizadas entrevistas semiestruturadas com cada professor, pautadas por um roteiro com tópicos indagando sobre a trajetória de vida do sujeito e sobre os significados pessoais atribuídos ao ser professor de História, gerando um material que foi gravado e posteriormente transcrito. As fontes geradas a partir desses instrumentos - os diários de campo e as entrevistas referentes a cada um dos cinco participantes foram organizadas e tratadas com base nos procedimentos gerais da análise de conteúdo (BARDIN, 2011), que recorre a exercícios sistemáticos e objetivos de descrição dos conteúdos de mensagens, de elaboração de categorias e unidades de sentido, a partir dos quais são feitas as inferências e interpretações.

\section{As representações sociais, a cidadania e a conscientização crítica}

Quando perguntados sobre os motivos da escolha profissional pelo ensino de História, os docentes normalmente evidenciam inquietações, incômodos ou insatisfações perante o mundo, elementos que são associados a características específicas da carreira e da disciplina História, carregando principalmente noções de justiça social, cidadania, formação humana e mudança social, como evidenciam os trechos das entrevistas a seguir:

[...] mas eu sempre tive essa visão muito assim, de querer mudar o mundo de alguma maneira. 'Ah, então beleza, como é que você vai mudar o mundo?' Ensinando, essa era a minha visão, né? Então, eu vou fazer História porque eu quero tanto mudar o mundo, que eu acho que a melhor maneira de você mudar o mundo vai ser educando, ensinando as pessoas. (Profa. Natália - nome fictício, entrevista em julho de 2014).

Resultado, pensei o seguinte: se na justiça meu pai não poderia reaver a terra, a gente poderia brigar para que houvesse uma conscientização política através da História, entendeu? (Profa. Maria Lia - nome fictício, entrevista em abril de 2014).

Uma das características mais associadas ao ensino de História são os fins e objetivos atribuídos a noções de construção de cidadania e conscientização crítica dos alunos, perspectivas presentes na documentação oficial curricular e investigadas em pesquisas da área. Essa perspectiva reconhece a autonomia e o 
papel do aluno como sujeito, considerando o modo como a educação histórica escolar deve proporcionar-Ihe diferentes maneiras de atuar na sociedade em que vive. Ela pode ser pensada como bastante próxima a alguns objetivos e características conferidas ao ensino de História a partir das décadas de 1980 e 1990 (BITTENCOURT, 2011), nos movimentos de renovação e de diversificação de conteúdos e metodologias, no seio dos debates educacionais durante o processo de redemocratização do Brasil.

Com a crise do governo militar e com o processo de redemocratização do Brasil, surgiram os movimentos de renovação e elaboração de novas propostas, tanto para a educação em geral como para o ensino de História. Fonseca (2011) destaca os debates de reformulação em São Paulo e Minas Gerais, enfatizando as análises críticas que posicionaram outros grupos sociais como sujeitos do processo histórico, organizando-os em conteúdos com clara inspiração em alguns conceitos e princípios marxistas, como modo de produção, classe dominante, apropriação do excedente, luta de classe etc. Para Gusmão (2004), o ensino de História assume um papel de destaque nos debates educacionais desse contexto, sobretudo nas frentes que defendiam o ensino como espaço de discussão e de luta sociocultural.

Dos anos 1990 em diante, verifica-se a busca de uma aproximação com o saber científico, com as mudanças historiográficas e seus debates mais recentes, de influência da tendência francesa "Nova História", passando a englobar os enfoques da história das mentalidades e do cotidiano. A flexibilização e diversificação de conteúdos e metodologias de ensino ganham progressivamente mais espaço, embora isso não signifique um rompimento completo com as práticas tidas como tradicionais, com a perspectiva linear ou cronológica, nem com o paradigma marxista de interpretação histórica (FONSECA, 2011).

Em relação a algumas pesquisas sobre essas transformações, Gusmão (2004) investigou oito professores de História atuantes em três cidades paulistas, verificando, nas gerações docentes mais novas, a tendência em priorizar a cidadania e o desenvolvimento de habilidades de leitura e escrita, em lugar da transmissão de conhecimento histórico e de noções de verdade. Cardoso (2007) discute os resultados de uma pesquisa de campo cujo objetivo foi compreender como os professores de História do Ensino Médio representam o saber histórico escolar que produzem cotidianamente na relação com seus alunos, com base na 
observação de aulas de docentes de São Paulo durante o ano letivo. O autor, analisando representações desses docentes, argumenta que os posicionamentos construídos em torno da conscientização e formação da cidadania teriam se tornado um "slogan educacional", surgido no contexto de abertura política do Brasil pós-ditadura e nos debates em torno da criação de um saber histórico escolar desde então:

[...] propagado tanto pelos professores quanto pelos documentos oficiais, reflete a confiança que se depositava na escola estatal como elemento-chave para a condução e manutenção da abertura política. Para que isso se concretizasse, era importante que os alunos tivessem um papel mais atuante nas escolas e, em particular, nas aulas de História. Assim, as propostas curriculares elaboradas nesse contexto remetem necessariamente à discussão em torno da criação de um saber histórico escolar (CARDOSO, 2007, p. 210).

As representações sociais em torno da noção de cidadão crítico ou cidadão pleno surgem recorrentemente nos significados relacionados ao ofício de professor de História, conforme registram os recortes das entrevistas a seguir:

Esse é justamente o eixo temático que eu trabalho com os alunos, é a formação da cidadania, a formação de cidadão. É a compreensão de si enquanto um ser pensante, um ser histórico, um ser que pensa, um ser que tem acesso aos seus direitos e aos seus deveres. Essa criança, para poder entender que o que ela tem hoje, os direitos que ela tem e os deveres que ela tem não brotaram do nada. Eles foram historicamente e socialmente construídos, e o que que aconteceu que pode levar à situação que a gente vive hoje (Profa. Natália - nome fictício, entrevista em julho de 2014).

Ao mesmo tempo, o ensino de História tem um papel importantíssimo na formação escolar do aluno, principalmente porque ele trabalha certas competências como a leitura, fundamental como a interpretação de texto, e também ele atua na visão crítica do aluno. Pelo menos essa é a proposta ideal dele e muita gente não consegue, mas essa é a proposta dele: atuar na visão crítica de mundo do aluno (Prof. Jessé - nome fictício, entrevista em novembro de 2014).

Então, acho que nada melhor do que História pra conscientizar alguém de alguma coisa, é o único conteúdo capaz de fazer isso. Eu sempre, você já deve ter percebido... é o único conteúdo que nos dá essa condição passado - presente, de tentar resgatar e ao mesmo tempo conscientizar do que que vale, do que é que pode, qual que é o nosso limite, né? (Profa. Maria Lia - nome fictício, entrevista em abril de 2014). 
Tal representação é ancorada, para usar o termo de Moscovici (2004), em características específicas atribuídas à história escolar e se realizaria por meio de uma ampliação da experiência vivida, da compreensão de diferentes aspectos da realidade cujo acesso se dá por meio do saber histórico escolar, o que resultaria na abertura de possibilidades de estar e de agir no mundo. Porém, que concepções de cidadania estão por trás dessas representações e como elas são articuladas no cotidiano escolar e nas práticas dentro de sala de aula?

\section{Cidadania, cidadanias e seus limites}

A noção de cidadania, que apareceu nos significados atribuídos ao trabalho docente na história ensinada, é algo que adquiriu importância e papel estratégico no seio dos debates sobre a democracia no Brasil, pós-fim do governo militar, em 1985, sendo utilizada por diferentes grupos sociais, imprensa, lideranças políticas e sindicais. Segundo Carvalho, em tal contexto "não se dizia mais 'o povo quer isto ou aquilo', diz-se 'a cidadania quer'. Cidadania virou gente. No auge do entusiasmo cívico, chamamos a Constituição de 1988 de Constituição Cidadã" (CARVALHO, 2002 , p. 7). Esse otimismo em torno da democratização das instituições que traria melhorias e justiça social, garantias de liberdade, de participação e de desenvolvimento, mostrou-se, ao longo do tempo, algo muito mais complexo do que aquilo que se esperava obter.

O conceito de cidadania não possui uma definição fixa, na medida em que possui historicidade, variando no tempo e no espaço, seja pelas mudanças que definem quem é ou não considerado cidadão e, mesmo dentro de um Estadonação, o conceito e a prática da cidadania vão se transformando, de acordo com o estatuto de cidadão estabelecido em uma população, conforme as tensões e conflitos que envolvem os diferentes grupos sociais e seus graus de participação na esfera pública. A concepção clássica se desdobra em três direitos: os civis (à vida, à liberdade, à propriedade, à igualdade perante a lei); os políticos (votar e ser votado, participar dos processos decisórios da sociedade) e os sociais (à saúde, à educação, ao trabalho e salário dignos, à participação na riqueza coletiva) (PINSKY; PINSKY, 2013). 
Embora a evolução da cidadania não siga uma sequência linear, nem única e nem progressiva, é possível constatar um processo de ampliação dos direitos ao longo da história no mundo ocidental analisando, desde os processos de lutas que envolveram a independência dos EUA e a Revolução Francesa, até os conflitos para a inclusão de grupos como as mulheres, as minorias étnicas, etárias, sexuais, conforme ressalta Pinsky e Pinsky (2013). Sua natureza histórica é indissociável do processo histórico de formação do Estado, pois "a luta pelos direitos, todos eles, sempre se deu dentro das fronteiras geográficas e políticas do Estado-nação" e "a cidadania tem a ver com a relação das pessoas com o Estado e com a nação", ressalta Carvalho (2002, p.12).

É preciso considerar ainda que a educação escolar tem papel fundamental como espaço de formação e promoção da cidadania:

\begin{abstract}
A escola fundamental reveste-se, assim, de uma dupla responsabilidade social: por um lado, é uma mediação indispensável para a cidadania, ao prover, de modo sistemático e organizado, a educação que atualiza historicamente as novas gerações; por outro, porque não pode dar conta de todo o saber produzido historicamente, ela precisa fazer isso de modo seletivo, priorizando aquilo que é mais relevante para a formação dos cidadãos. Tudo isso empresta uma extrema seriedade àquilo que a escola se propõe a fazer e àquilo que ela de fato faz (PARO, 1999, p. 110).
\end{abstract}

Trata-se, dessa forma, de um conceito complexo, não-fixo e com múltiplas dimensões e, quando pensado dentro do campo da educação e do ensino de História, apresenta ainda mais dinamismo. Magalhães (2009), discutindo as acepções de cidadania nas propostas curriculares contidas nos Parâmetros Curriculares Nacionais relativos à História e aos Temas Transversais - formulados pelo governo federal na década de 1990 - observa a ambiguidade no conceito que, por vezes, é compreendido como a ampliação dos direitos (civis, políticos, sociais, humanos, etc.) e em outros casos, enfatiza a questão da cultura e da diferença. Além disso, segundo o autor:

Para os PCNs, a questão da cidadania hoje está ligada à questão da democracia. Se a democracia é compreendida num sentido restrito, de regime político, o significado atribuído à cidadania está relacionado aos direitos civis e políticos. Num sentido amplo, como forma de sociabilidade, a cidadania adquire novas dimensões, englobando os direitos sociais e os direitos humanos (MAGALHÃES, 2009, p.177). 
Considerando tais aspectos multifacetados da noção de cidadania, podemos afirmar que as situações observadas em sala de aula e registradas em diário de campo com os cinco professores participantes da nossa pesquisa demonstram alguns problemas e tensões, sobretudo com relação às perspectivas de cidadania afirmadas nas entrevistas. Uma situação representativa que podemos citar envolveu uma aula da professora Natália (nome fictício) sobre aspectos da crise da Idade Média e a formação dos Estados Nacionais na Europa, junto a uma turma de 70 ano do ensino fundamental. A explicação da docente sofria constantes interrupções e descontinuidades, diante do comportamento indisciplinado e da falta de atenção da turma, obrigando-a a interromper a explicação para chamar a atenção dos alunos. ${ }^{3}$

Em determinado momento de sua fala, a professora enfatiza a necessidade de colaboração da turma e a importância da matéria para a formação dos alunos, e no esforço de ressaltar esses aspectos, a docente passa a argumentar a relevância do aprendizado da História, dirige-se aos alunos dizendo que "o verdadeiro sentido da disciplina é formar o cidadão pleno". Em tal situação, a representação da cidadania associada ao ensino emerge em uma tentativa de tornar familiar o não-familiar, ou seja, conscientizar seus alunos da importância da disciplina e do conteúdo que estava sendo discutido.

Embora a professora não tenha aprofundado a discussão e nem explicado aos seus alunos o que ela quis dizer com cidadania plena, essa representação da formação do cidadão como fruto do próprio trabalho pode ser pensada como um ponto de estabilização, de busca de equilíbrio diante de uma situação complexa, do desafio de construir a aula de modo a atingir os alunos. Posturas semelhantes também foram verificadas no cotidiano de outros professores, novamente diante de situações de indisciplina na gestão da sala de aula, nas quais os educadores tiveram que argumentar sobre a importância do próprio trabalho e dos conteúdos discutidos, ancorando tais aspectos na ideia de formação cidadã e de sua relevância para a vida social.

Outras ocorrências nos mostraram que a noção de cidadania, embora apareça recorrentemente nos discursos das entrevistas, pode não estar tão clara

\footnotetext{
3 Registro em diário de campo datado de abril de 2014. As falas posteriores (em aspas) são provenientes do mesmo recorte temporal de observação.
} 
para os docentes no cotidiano da sala de aula. Nesse sentido, um segundo evento representativo a ser destacado envolveu o professor Carlos Andrade (nome fictício) mediando uma atividade na qual seus alunos, do $8^{\circ}$ ano do ensino fundamental, deveriam procurar no dicionário o significado das palavras que não haviam compreendido. ${ }^{4}$ Em determinado momento da tarefa, uma aluna vem do fundo da sala, aproxima-se da mesa do professor, e afirma estar confusa sobre a definição do termo cidadania.

Diante dos constantes pedidos de auxílio, feitos simultaneamente pelos alunos, perante a urgência e a incerteza que caracterizam a complexidade das práticas docentes, o professor acaba não explicando as diferentes dimensões da noção de cidadania, aceitando a definição mais superficial referente "àquele que habita uma cidade". Essa e outras ocasiões evidenciam momentos em que os professores não aprofundaram a discussão e não definiram melhor a ideia de cidadania. Porém, é preciso ressaltar que as circunstâncias que envolviam as aulas quase sempre não eram as mais favoráveis para isso, havendo dificuldades como a indisciplina, a violência escolar, e os problemas de leitura, e de compreensão de texto, presentes na maioria dos estudantes. A partir disso, surge a questão: Quais os limites para se demandar a construção da cidadania como atribuição do ofício de professor diante das condições atuais do ensino na educação pública?

As representações dos docentes quanto à cidadania, que podem ser inferidas a partir do cotidiano das salas de aula, revelam algumas compreensões pouco densas e pouco desenvolvidas, em contraste com aquilo que foi colocado nas entrevistas. Além disso, outras ocasiões nos mostraram que alguns significados atribuídos à formação cidadã através da escola são associados à ascensão socioeconômica, à aquisição de bens materiais, e à preparação para o mercado de trabalho, sobretudo quando os professores ressaltam que "a única forma de sobrevivência é a qualificação", ou "que é preciso ter o seu carro, sua casa". Tais perspectivas podem ser pensadas como algo que, em certa medida, está afastado dos objetivos formativos relacionados às ideias de cidadania e de conscientização crítica.

Paro (1999), ao defender uma concepção de educação como a constituição cultural dos sujeitos, através da apropriação da herança cultural anteriormente

\footnotetext{
4 Registro em diário de campo datado de maio de 2014.
} 
produzida, problematiza essa visão de mundo na qual a escola deve contribuir com algum retorno para o sistema econômico, sobretudo contra o discurso de que ela deva ser um meio de ascensão social que contribua para o sistema produtivo e sirva ao capital:

Quando se examina a prática e se analisa com frieza o que a escola procura fazer, na ação de seus professores e no atendimento às aspirações e expectativas de seus usuários, o que aparece sempre como perspectiva essencial é o mercado de trabalho (agora, visando o emprego imediato; no futuro, visando à preparação para a universidade). [...] Do lado dos usuários, parece plausível essa expectativa, diante da já mencionada falta de opções, que não o trabalho assalariado, para ganhar a própria vida. Mas, do lado da escola, é preciso questionar se ela deve ater-se com tanta ênfase a essa tarefa (PARO, 1999, p. 110)

As transformações das últimas décadas do século $X X$, sobretudo durante os anos 1990, registram a progressiva inserção do Brasil na lógica da globalização, do mercado mundial, assim como a formulação de programas e políticas conforme as diretrizes de organismos internacionais como o Banco Mundial. Tais transformações certamente têm tornado o trabalho docente mais complexo, assim como trazem novos elementos aos processos representacionais dos professores.

Para Frigotto (2001), a democracia brasileira e o sistema educativo seriam de natureza mutilada, marcados por projetos societários das forças conservadoras e subordinadas ao grande capital. Na década de 1990, o projeto conservador teria sido baseado nas demandas do capital e da ideologia neoliberal, caracterizando um retrocesso no que concerne à mercantilização da educação no plano das reformas educativas. Logo, o ideário vigente é o de que a liberdade de mercado conduziria à prosperidade, naturalmente excluindo os incompetentes e inadequados a competir. Para o autor, o ajuste à nova ordem mundial se daria mediante três estratégias: desregulamentação, descentralização/autonomia e privatização. Dessa forma, o campo educativo seria estruturado de acordo com as concepções produtivistas e mercantilistas, enfatizando o desenvolvimento de competências e habilidades voltadas à empregabilidade. Tais concepções atravessariam a criação da Lei de Diretrizes Bases da educação e de programas como o FUNDEF (Fundo de Manutenção e Desenvolvimento do Ensino Fundamental e de Valorização do Magistério), assim como os Parâmetros Curriculares Nacionais. 
As repercussões dessa conjuntura podem ser verificadas na difusão das noções e perspectivas de "qualidade total", "competitividade" e posturas individualistas. Podemos afirmar que talvez exista um grau de repercussão sobre os processos representacionais dos professores e sobre as atribuições conferidas ao próprio ofício, no sentido de orientar os objetivos profissionais de acordo com as demandas de formação para o mercado, de exames de processos seletivos e de acesso ao ensino superior, em detrimento de uma formação mais integral.

Portanto, o exercício analítico de comparar as representações sociais em torno da noção de cidadania que surgiram nas entrevistas e nas práticas pedagógicas cotidianas nos evidencia, principalmente, algumas tensões e fragilidades dessas concepções, algo que está em estreita relação com o contexto socioeconômico mais amplo e com as condições de trabalho e de carreira desses professores.

\section{Considerações finais: as representações como pontos de estabilização}

As concepções de cidadania dos docentes, aqui discutidas, podem ser pensadas como representações sociais pelos seguintes motivos: emergem em situações de interação, diante de um entrevistador, ou diante de vinte ou trinta alunos, ou diante de si próprio no exercício profissional cotidiano; envolvem elementos afetivos, cognitivos e sociais - escolhas, campos de ação, legitimação, debates acerca de objetos sociais (educação, função do ensino de História, cidadania, etc.); são processos articulados em movimentos que tornam convencionais objetos, temas, assuntos, convertendo em familiar o não-familiar (a cidadania, o motivo da escolha profissional, a importância do ensino de História para si mesmo e para os outros). São, portanto, representações cujo caráter social diz respeito à sua função de mediação entre o sujeito e o mundo social.

No caso dos professores envolvidos em nosso estudo, podemos afirmar que as representações focalizam determinadas facetas da cidadania. Ao falarem, nas entrevistas, em "construir cidadão, sujeito crítico", em "quem é a gente hoje, e como a gente se constitui enquanto cidadão", há uma tendência em valorizar a capacidade de formular julgamentos críticos sobre o mundo social e as formas de 
ação concreta dos indivíduos, principalmente no espaço público, o que realça a dimensão dos direitos políticos. Já quanto às representações verificadas, em sala de aula, a partir das quais são inferidas noções de cidadania, podemos compreender um destaque dado à dimensão dos direitos sociais ("ter sua casa, seu carro, seu emprego", "a única forma de sobrevivência é a qualificação"), sobretudo no que diz respeito à preparação para o ingresso no mundo do trabalho, o que pode ser problemático porque reflete a "mercantilização do ensino" mas, ao mesmo tempo, pode ser a forma encontrada para inspirar sentido aos conteúdos trabalhados, para aproximar e conseguir a participação e a colaboração de dezenas de crianças, jovens e adultos, presentes nos cenários das salas de aula.

Essas representações sociais docentes apresentam alguns contrapontos importantes que certamente afetam os processos de elaboração de significados. Um deles é o trajeto histórico da História como disciplina escolar no Brasil, o qual envolve as discussões e as lutas socioculturais que emergiram no campo educacional durante o processo de redemocratização do Brasil, conforme afirmamos acima. Foi no interior dessas transformações - que afetaram o ensino de História nas últimas décadas do século XX - que surge a definição dos contornos de um saber histórico escolar, assim como as propostas de formação de cidadania e conscientização crítica dos estudantes. Outro contraponto pode ser observado a partir do movimento mais amplo da globalização e das reformas neoliberais na educação, o que contribui para a difusão de um ideário que aproxima o ensino escolar da formação e preparação para o mercado.

Problematizar as representações, e suas perspectivas de cidadania, não significa culpar os docentes nem dizer que estão fundamentando seu trabalho em significados errados ou prejudiciais, pelo contrário, a questão aqui pode ser conduzida no sentido de pensarmos em que medida essas representações em tensão também podem ser pensadas como resultados de estratégias surgidas no cotidiano, como respostas às demandas, às contradições e condições do próprio contexto educacional recente na rede estadual mineira. Em que medida esses processos representacionais podem ser pensados como formas de negociação e de sobrevivência dentro do ofício no ensino de História? Foi possível observar que eles permitem uma estabilização das ideias sobre o próprio trabalho, como forma 
de reequilibrar a própria identidade diante das condições precárias de salário e carreira, atribuindo sentido à profissão.

Essas representações sobre cidadania ainda nos mostram possíveis caminhos para propostas e estratégias de formação continuada, uma vez que os docentes valorizam essa dimensão do trabalho no ensino de História, então seria interessante propor mais investimento teórico e mais pesquisas sobre esse percurso, aproveitando uma temática que está presente no universo simbólico e cultural dos professores. Tal caminho pode converter-se não só em uma forma de empoderamento dos docentes da rede básica pública, fortalecendo o laço entre pesquisa e ensino de História, e valorizando o ofício na educação, mas também como forma de consertar distorções e imprecisões que comprometem a compreensão das diferentes dimensões da cidadania.

Por fim, é preciso considerar que as discussões sobre formação cidadã e suas relações com a educação também esbarram em questões complicadas e, talvez, incômodas, como: Quais as funções ou objetivos do ensino público? Que tipo de cidadão a escola pública pretende formar? Quais perspectivas de cidadania têm sido privilegiadas: a de cidadão-consumidor, de cidadão-eleitor, de cidadãotrabalhador ou de cidadão crítico? Qual o papel do ensino de História na educação para a cidadania? As representações sociais são apenas uma das formas de aproximação e de estudo desses processos.

\section{Referências}

ALVEZ-MAZZOTTI, Alda Judith. Representações sociais: aspectos teóricos e aplicações à educação. Revista Múltiplas Leituras, São Paulo, v. 1, n.1, p. 18-43, jan./jun. 2008.

ANDRÉ, Marli. Etnografia da prática escolar. Campinas, SP: Papirus, 1995.

BARDIN, Laurence. Análise de conteúdo. Tradução de Luís Antero Reto. São Paulo: Edições 70, 2011.

BITTENCOURT, Circe Maria. Ensino de história: fundamentos e métodos. São Paulo: Cortez, 2011.

CARDOSO, Oldimar Pontes. Representações dos professores sobre saber histórico escolar. Cadernos de Pesquisa, São Paulo, v. 37, n. 130, p. 209-226, jan./abr. 2007. 
CARVALHO, José Murilo de. Cidadania no Brasil: o longo caminho. 3. ed. Rio de Janeiro: Civilização Brasileira, 2002.

GUARESCHI, Pedrinho; JOVCHELOVITCH, Sandra (Org.). Textos em representações sociais. 12. ed. Petrópolis, RJ: Vozes, 2011.

GUSMÃO, Emery Marques. Memórias de quem ensina história: cultura e identidade docente. São Paulo: Editora UNESP, 2004.

FONSECA, Thaís Nívia de Lima e. História e ensino de história. Belo Horizonte: Autêntica, 2011.

FRIGOTTO, Gaudencio Reformas educativas e retrocesso democrático no Brasil nos anos 90. In: LINHARES, Célia. Os professores e a reinvenção da escola. São Paulo: Cortez, 2001. p. $57-80$.

JODELET, Denise. O movimento de retorno ao sujeito e a abordagem das representações sociais. Sociedade e Estado, Brasília, v. 24, n. 3, p. 679-712, set./dez. 2009.

JODELET, Denise. Representações sociais: um domínio em expansão. In: . (Org.). As representações sociais. Paris: PUF, 1989. p. 31-61.

MADEIRA, Margot Campos. Representações sociais e educação: algumas reflexões. Natal: EDUFRN, 1997.

MAGALHÃES, Marcelo de Souza. História e cidadania: por que ensinar história hoje? In: ABREU, Marta; SOIHET, Raquel (Org.). Ensino de história: conceitos, temáticas e metodologia. Rio de Janeiro: Casa da Palavra - FAPERJ, 2009. p. 168-186.

MOSCOVICI, Serge. Representações sociais: investigações em psicologia social. 2. ed. Petrópolis: Vozes, 2004.

PARO, Vitor Henrique. Parem de preparar para o trabalho!!! Reflexões acerca dos efeitos do neoliberalismo sobre a gestão e o papel da escola básica. In:

FERRETTI, Celso João et al. (Org.). Trabalho, formação e currículo: para onde vai a escola. São Paulo: Xamã, 1999. p. 101-120.

PINSKY, Jaime; PINSKY, Carla Bassanezi (Org.). História da cidadania. São Paulo: Contexto, 2013. 